\title{
Small Intestinal Fibrosarcoma
}

National Cancer Institute

\section{Source}

National Cancer Institute. Small Intestinal Fibrosarcoma. NCI Thesaurus. Code C5336.

A usually aggressive malignant neoplasm arising from the small intestine. It is characterized by the presence of spindle-shaped fibroblasts and collagenous stroma formation in a herring bone growth pattern. 